\title{
PERTANGgungJaWABAN PIDANA PELAKU TINDAK PIDANA PENGANIAYAAN YANG DIRENCANAKAN (Studi Kasus Putusan Pengadilan Negeri Bangli Nomor 19/pidB/2019/PNBLI)
}

\author{
I Dewa Gede Windhu Indrakusuma, I Made Arjaya, Ni Made Sukaryati Karma \\ Fakultas Hukum Universitas Warmadewa, Denpasar-Bali, Indonesia \\ windhudewa26@gmailcom, imdarjaya@gmailcom, sukariati64@gmailcom
}

\begin{abstract}
Abstrak
Penganiayaan adalah suatu perbuatan yang menimbulkan luka ataupun rasa sakit kepada seseorang yang dilakukan dengan sengaja. Penganiayaan terdiri dari penganiayaan ringan dan penganiayaan berat. Penelitian ini bertujuan untuk mengetahui sanksi pidana terhadap pelaku tindak pidana penganiayaan yang direncanakan dan untuk menaganalisis pertimbangan putusan hakim terhadap pelaku tindak pidana penganiayaan yang direncanakan. Jenis penelitian ini adalah penelitian hukum normatif dengan menggunakan pendekatan perundang-undangan. Teknik pengumpulan bahan hukum dilakukan dengan teknik wawancara. Hasil penelitian menunjukan bahwa sanksi pidana terhadap pelaku penganiayaan yang direncanakan adalah pidana penjara maksimal empat tahun sebagaimana diatur dalam pasal 353 ayat 1 KUHP sedangkan dalam kasus putusan Nomor 19/pidB/2019/PNBLI pelaku I Made Merta dikenakan hukuman pidana penjara selama empat bulan sesuai dalam pasal 353 ayat 1 KUHP dimana unsur-unsur yang terdapat didalamnya semua terpenuhi. Kemudian, pertimbangan hakim dalam pelaku tindak pidana penganiayaan yang direncanakan antara lain pertimbangan yang bersifat Yuridis yaitu hal-hal yang memberatkan dan hal-hal yang meringankan sedangkan dalam studi kasus putusan Nomor 19/pidB/2019/PNBLI hakim lebih mempertimbangkan riwayat dari terdakwa yaitu terdakwa sopan dan mengaku terus terang perbuatannya di persidangan belum pernah dihukum dan sudah ada perdamaian antara saksi korban I Gede Jasa, sehingga hakim menjatuhkan hukuman Pasal 353 KUHP yaitu selama empat (4) bulan.
\end{abstract}

Kata kunci: Penganiayaan berencana, putusan hakim, sanksi pidana, Tindak Pidana

\begin{abstract}
Maltreatment is an act that causes injury or pain to someone which is done on purpose. The maltreatment consisted of light maltreatment and severe torture. This study aims to determine the criminal sanctions against the planned perpetrators of maltreatment and to analyze the considerations of the judge's decision against the perpetrators of the planned maltreatment. This type of research is normative legal research using a statutory approach. The technique of collecting legal materials is done by interviewing techniques. The results of the study show that the criminal sanction against the perpetrator of the planned maltreatment is a maximum of four years in prison as regulated in Article 353 paragraph 1 of the Criminal Code, while in the case of decision Number 19 / pidB / 2019 / PNBLI, the perpetrator I Made Merta is subject to imprisonment for four months according to Article 353 paragraph 1 of the Criminal Code where the elements contained therein are all fulfilled. Then, the judges' considerations in the perpetrators of the planned maltreatment included considerations of a juridical nature, namely things that were burdensome and things that were mitigating, whereas in the case study decision Number 19 / pidB / 2019 / PNBLI the judge considered more about the history of the defendant, namely the defendant. polite and admit that his actions in court have never been convicted and there has been peace between witnesses victim I Gede Jasa, so the judge sentenced Article 353 of the Criminal Code, which is four (4) months. Keywords: Criminal Sanction, Criminal Act, Judge Verdict, Planned Maltreatment
\end{abstract}

\section{PENDAHULUAN}

Berbagai macam tindak pidana dapat dilihat sebagai perbuatan pidana. Tindak pidana yang telah diatur dalam KUHP, dimana secara nyata memiliki ancaman berupa saksi pidana. Suatu tindak pidana menjadi sebuah wujud atas sikap masyarakat yang tetap harus diperhatikan secara bersama demi terwujudnya kehidupan masyarakat yang aman.

Diantara wujud tindak pidana yang kebanyakan terjadi di sekitar lingkungan masyarakat yaitu bentuk kekerasan seperti penganiayaan. Maraknya tindak pidana penganiayaan di lingkungan masyarakat menunjukan bahwa tindak pidana penganiyaan itu tidak jauh dari sifat masyarakat yang 
tidak bisa dikendalikan dengan sebagaimana mestinya. Penyebab hal tersebut karena tingkat pendidikan masyarakat yang masih rendah. Di sisi lain, dikarenan factor lingkungan yang jahat.

Dalam Putusan PN Bangli No 19/pidB/2019/PNBLI terdapat kasus penganiayaan yang melibatkan I Made Merta Als Gadig (terdakwa) pada Kamis 11 Oktober 2018 perkiraan pukul 1800 wita berlokasi di Banjar Dausa Desa Dausa, Kecamatan Kintamani, Kabupaten Bangli telah melakukan Penganiayaan dengan direncanakan terlebih dahulu terhadap saksi korban I Gede Jasa Als Mangku Gede Jasa.

Dimana pada hari Kamis tanggal 11 Oktober 2018 I Made Merta Als Gadig (terdakwa) menghadiri acara resepsi pernikahan saksi korban I Gede Jasa Als Mangku Gede Jasa dan disana I Made Merta Als Gadig (terdakwa) melakukan penganiayaan dengan cara menarik rambut I Gede Jasa Als Mangku Gede Jasa dan mendorong hingga terjatuh kemudian dipukuli kearah muka sebanyak 3 (tiga) kali dengan menggunakan tangan kanan Tak hanya itu I Made Merta Als Gadig (terdakwa) juga menyayatkan pisau pengutik di leher sebelah kiri I Gede Jasa Als Mangku Gede Jasa Dalam kasus ini terdakwa diancam dengan Pasal 353 KUHP.

Majelis Hakim hanya menjatuhi pidana penjara terhadap korban selama 4 (empat) bulan. Melihat korban yang mengalami luka robek pada hidung dan luka gores pada leher kiri akibat sayatan pisau pengutik tersebut tergolong cukup parah. Namun, hukuman yang dijatuhkan tergolong ringan. Dari sisi lain, terdakwa juga menggunakan senjata tajam yang dapat mengancam nyawa korban. Penanganan suatu tindak pidana terjadi semacam disparitas, sehingga masih banyak orang yang berani melakukan tindak pidana penganiayaan.

Penelitian yang serupa dengan penelitian sekarang ini, yaitu pertama tentang tinjauan yuridis terhadap tindak pidana penganiayaan yang direncanakan terlebih dahulu (Wahab, 2016) dan kedua tentang tanggung jawab pidana pelaku tindak pidana penganiayaan mengakibatkan kematian yang melakukan pembelaan diri terhadap harta benda (Sari, 2019).

Berdasarkan uraian permasalahan diatas maka penelitian baru ini bertujuan untuk mengetahui sanksi pidana terhadap tindak pidana penganiayaan yang direncanakan dan menganalisis pertimbangan Hakim dalam memberi putusan terhadap pelaku tindak pidana penganiayaan yang direncanakan.

\section{METODE PENELITIAN}

Jenis penelitian ini menggunaka hukum normative. Penelitian hukum normatif ialah penelitian hukum yang dimana konsepnya telah tertulis baik itu dalam perundang-undangan ataupun norma yang menjadi tolak ukur perilaku masyarakat yang wajar (Amirudin \& Asikin, 2012). Penelitian hukum yuridis normatif atau penelitian hukum normatif pada dasarnya merupakan suatu kegiatan yang akan mengkaji aspekaspek internal dari hukum positif (Benuf \& Azhar, 2020).

Sumber bahan hukum yang digunakan terbagi atas Bahan Hukum Primer adalah bahan hukum yang utama yang menjadi dasar kajian ini. Bahan Hukum sekunder adalah adalah bahan hukum yang digunakan untuk menunjang atau membantu dalam memberikan pemahaman- pemahaman dan gambaran-gambaran serta teori-teori hukum yang di gunakan untuk mengulas dan memecahkan persoalan-persoalan yang akan di teliti di dalam penelitian ini. Dalam memperoleh bahan hukum primer, peneliti menggunakan metode interview atau wawancara dengan hakim sekunder dengan metode penelitian studi kasus di Pengadilan Negeri Bangli dalam bentuk Putusan.

\section{HASIL DAN PEMBAHASAN}

\section{Sanksi Pidana Terhadap Pelaku Tindak Pidana Penganiayaan yang Direncanakan}

Sanksi merupakan hasil yang diterima akibat malakukan suatu pelanggaran yang telah diatur UndangUndang (Waluyo, 2008). Sanksi terbagi menjadi sanksi administrative, sanksi perdata ataupun sanksi pidana (Oktaliza, 2012). Sanksi Administratif merupakan teguran tertulis. Sanksi ini diberikan kepada pelaku usaha dalam hal penanggung jawabnya atas pelanggaran aturan perundang- undangan ataupun ketentuan dalam izin lingkungan. Sanksi perdata adalah berupa ganti rugi. Sementara, sanksi pidana ialah suatu perbuatan atas dilanggarnya ketentuan pidana yang berupa pidana dan/atau tindakan (Hamzah, 2006).

Penganiayaan adalah suatu perbuatan yang menimbulkan luka ataupun rasa sakit kepada seseorang yang dimana dilakukan dengan sengaja. Menurut Handoko (2020) bahwa penganiayaan merupakan suatu bentuk kejahatan yang sangat diperhatikan oleh hukum, karena pelanggaran ini sangat rentan terjadi dikalangan masyarakat. Penganiayaan terdiri dari penganiayaan ringan dan penganiayaan berat. 
Penganiyaan ringan ialah perbuatan yang tidak menghalangi seseorang dalam menjalankan kewajibannya untuk melakukan suatu pekerjaan. Penganiyaan berat ialah perbuatan yang menimbulkan seseorang mengalami luka serius ataupun kecacatan sehingga seseorang tidak dapat menjalankan kewajibannya setiap hari.

UU tidak memberikan pengertian dari penganiyaan. Akan tetapi, dalam yurisprudensi penganiayaan ialah perbuatan sengaja yang menyebabkan rasa sakit ataupun mendapatkan luka kepada orang lain. Apabila luka lebam yang dideritanya tidak menjadikan penghalang untuk melaksanakan kewajiban pekerjaannya sehingga perbuatan tersebut dianggap penganiyaan ringan yang diatur dalam Pasal 352 KUHP. Namun, berbeda halnya dengan penganiayaan yang telah direncanakan terlebih dahulu.

UU tentang penganiayaan berencana telah diatur dalam Pasal 353 KUHP. Unsur-unsurnya ialah perbuatan tersebut telah direncanakan sebelum pelaku melakukan perbuatannya. Contoh kasus nyata yaitu dalam Putusan PN Bangli No 19/pidB/2019/PNBLI terdapat kasus penganiayaan yang melibatkan I Made Merta Als Gadig (terdakwa). Dalam putusan tersebut diketahui bahwa terdakwa melakukan penganiayaan dengan cara menarik rambut I Gede Jasa Als Mangku Gede Jasa dan mendorong hingga terjatuh kemudian dipukuli kearah muka dilakukan tiga kali menggunakan tangan kanan. Tidak hanya itu, I Made Merta Als Gadig (terdakwa) juga menyayatkan pisau pengutik di leher sebelah kiri I Gede Jasa alias Mangku Gede Jasa. Sehingga, korban mengalami luka robek pada hidung dan luka gores pada leher kiri akibat sayatan pisau pengutik tersebut. Terdakwa dihukum berdasarkan Pasal 353 KUHP tentang penganiayaan yang direncanakan dengan hukuman pidana penjara selama 4 bulan.

\section{Pertimbangan Hakim dalam Memberi Putusan terhadap Pelaku Tindak Pidana Penganiayaan yang Direncanakan}

Pertimbangan hakim ialah pendapat yang dipergunakan hakim untuk suatu pertimbangan dimana akan menjadi landasan hakim untuk manjatuhkan sebuah perkara dalam persidangan. Putusan hakim pada praktiknya dipersidangan sebelum pertimbangan yuridis ini dibuktikan fakta-fakta hukum yang terungkap dalam persidangan akan terterlebih dahulu akan ditarik oleh hakim. Hakim mengambil sebuah kesimpilan yaitu sebagai sebuah pertimbangan yuridis untuk menegaskan kembali fakta-fakta yang telah terungkap (Wijayanto, 2012). Hakim dalam menjatuhi hukuman pidana tidak boleh lebih sedikit dari batas yang telah ditentukan ataupun sebaliknya tidak boleh lebih tinggi menjatuhi hukuman yang telah diatur dalam undang-undang (Rifai, 2010) selain itu hakim harus mengambil keputusan yang sesuai (Fitriani, 2017).

Adapun yang menjadi pertimbangan dalam perkara kekerasan fisik dalam lingkup rumah tangga yang mengakibatkan luka-luka berdasarkan Putusan Pengadilan Negeri Bangli Nomor 19/pidB/2019/PNBLI. Terdakwa diajukan ke persidangan di Pengadilan Negeri Bangli oleh Jaksa Penuntut Umum yang telah didakwa dengan dakwaan subsidairitas melanggar ketentuan Pasal 353 ayat (1) KUHP tentang Penganiayaan dengan rencana lebih dulu. Untuk membuktikan dakwaannya, Jaksa Penuntut Umum telah mengajukan 3 (tiga) orang saksi yaitu 1) I Gede Jasa, 2) Ni Komang Sulendri, 3) I Nyoman Widana yang telah memberikan keterangan dibawah sumpah di depan persidangan termuat dalam berita acara persidangan. Barang bukti yang diajukan Jaksa Penuntut Umum sebagai berikut:

1. Satu buah pisau (pengutik) bergagang kayu dengan panjang kurang lebih $255 \mathrm{~cm}$

2. Surat Visum et Repertum Nomor: 440/355/Yankes tanggal 20 Oktober 2018 dikeluarkan oleh UPT Puskesmas Kintamani I dan ditandatangani oleh dr Ni Made Dewi Desiani.

Dikarenakan dakwaan telah tersusun subsidairitas maka Majelis Hakim akan mempertimbangkan terlebih dahulu. Mempertimbangkan dakwaan Primair Penuntut Umum sebagaimana yang diatur pada Pasal 353 ayat (1) KUHP tentang Penganiayaan dengan rencana lebih dulu yang unsur-unsurnya sebagai berikut.

1. Unsur Barang Siapa

Menimbang bahwa pengertian dari setiap orang ialah subjek hukum yang memiliki hak dan kewajiban dimana dia dapat menanggung setiap perbuatannya di dalam suatu perkara yang disangka atau didakwa sebagai pelaku suatu tindak pidana. Dalam perkara ini telah dihadapkan ke persidangan, terdakwa I Made Merta alias Gadig yang identitasnya telah dibacakan diawal persidangan dan dibenarkan oleh terdakwa dan juga dibenarkan oleh saksi-saksi, sehingga tidak terjadi kesalahan. Terdakwa dapat menjawab segala pertanyaan dengan keadaan sehat jasmani dan rohani. 
2. Dengan sengaja

Menimbang bahwa sesuai dengan fakta hukum yang di dapatkan dalam persidangan bahwa pada sesuai dengan keterangan saksi korban, I Gede Jasa alias Mangku Jasa. Saksi Ni Komang Sulendri dan saksi Nyoman Widana yang pada pokoknya menerangkan bahwa terdakwa dengan sadar telah memukul dengan tangan mengepal ke arah muka korban, I Gede Jasa alias Mangku Jasa, sebanyak 3 (tiga) kali yang mengenai hidung korban hingga mengeluarkan darah dan menyayat leher korban, I Gede Jasa alias Mangku Jasa, menggunakan 1 (satu) buah pisau pengutik hingga terluka dan mengeluarkan darah.

3. Melakukan penganiayaan

Menimbang bahwa sesuai dengan fakta hukum yang di dapatkan dalam persidangan bahwa pada hari Kamis tanggal 11 Oktober 2018 sekitar pukul 1800 wita bertempat di Br Dausa Ds Dausa Kec. Kintamani, Kab. Bangli. Terdakwa, I Made Merta alias Gadig, telah melakukan penganiayaan terhadap saksi korban, I Gede Jasa alias Mangku Jasa, dengan cara memukul dengan tangan mengepal ke arah muka korban, I Gede Jasa alias Mangku Jasa, sebanyak 3 (tiga) kali yang mengenai hidung korban hingga mengeluarkan darah dan menyayat leher korban, I Gede Jasa alias Mangku Jasa, menggunakan 1 (satu) buah pisau pengutik hingga terluka dan mengeluarkan darah.

Menimbang: bahwa setelah kejadian tersebut kemudian saksi I Gede Jasa alias Mangku Jasa, berobat ke Puskesmas dan dibuatkan surat Visum et Repertum Nomor: 440/355/yankes tanggal 20 Oktober 2018 yang dikeluarkan oleh UPT Puskesmas Kintamani I serta di buat dan ditandatangani oleh dr. Ni Made Dewi Desiani dengan hasil pemeriksaan luka sebagai berikut:

a. Terdapat luka robek pada hidung tepat pada garis pertengahan batang hidung berukuran diameter nol koma lima sentimeter kali satu sentimeter.

b. Terdapat luka gores pada leher kiri lima sentimeter dan daun telinga kiri bagian bawah berukuran tiga koma lima sentimeter berwarna kemerahan.

c. Terdapat luka gores pada leher kiri bagian atas tiga sentimeter dari daun telinga kiri bagian bawah berukuran panjang tiga koma lima sentimeter dengan terdapat nampak jaringan di atas luka. Pada korban laki-laki berusia lima puluh tahun ditemukan lukaluka yang di sebabkan kekerasan benda tumpul yang tidak menimbulkan penyakit atau halangan untuk melakukan pekerjaan jabatan atau pencaharian.

4. Unsur dengan rencana lebih dahulu

Menimbang bahwa Penganiayaan ringan ialah suatu perbuatan yang tidak menyebabkab luka berat sehingga korban tidak terhalang dalam menjalankan pekerjaannya. Apabila korban tidak terhalang dalam menjalankan pekerjaannya maka dikategorikan penganiyaan biasa.

Menimbang bahwa walaupun demikian, jika perbuatan itu dilakukan dengan di pikirkan lebih dahulu (met voor bedachten rade) maka ketentuan tentang penganiayaan ringan tidak berlaku (Pasal 353 KUHP). Menimbang bahwa Prof. Simons menyatakan unsur Voorbedachten rade itu dianggap sebagai seorang pelaku telah memenuhinya apabila keputusannya untuk melakukan suatu tindakan kejahatan telah ia rancang dalam situasi aman dan juga dalam waktu itu ia telah menghitung hasil perbuatannya yang akan dilakukan (Simons Leerboek I hal 263).

Menimbang bahwa menurut Mr. MH Tiirtamidjaja memberikan pengertian perencanaan lebih dahulu (voor bedachten rade) ialah suatu jangka waktu dalam merencanakan rencananya dengan tenang sebelum ia melaksanakannya direncanakan lebih dulu adalah bentuk khusus dari kesengajaan (Opzettielijk) dan merupakan alasan pemberat pidana pada penganiayaan yang bersifat subjektif.

Menimbang bahwa berdasarkan keterangan saksi I Gede Jasa alias Mangku Gede Jasa, saksi Ni Komang Sulendri, saksi Nyoman Widana dan keterangan terdakwa bahwa pada hari Kamis tanggal 11 Oktober 2018 sekitar pukul 1800 WITA bertempat di Br Dausa Ds Dausa, Kec. Kintamani, Kab. Bangli. Terdakwa, I Made Merta alias Gadig, telah melakukan penganiayaan terhadap saksi korban, I Gede Jasa alias Mangku Gede Jasa dengan cara memukul dengan tangan mengepal ke arah muka korban, I Gede Jasa alias Mangku Jasa, sebanyak 3 (tiga) kali yang mengenai hidung korban hingga mengeluarkan darah.

Saat tiba di rumah, kemudian terdakwa menonton TV. Namun, kembali terdakwa teriingat kata-kata korban, I Gede Jasa alias Mangku Jasa, yang membuat terdakwa tersinggung. Setelah 
itu, terdakwa mengambil pisau (pengutik) yang ada di atas televise. Terdakwa mengendarai sepeda motor untuk menemui kembali korban, I Gede Jasa alias Mangku Jasa, di rumah dengan membawa pisau (pengutik).

Setelah sampai di rumah korban, I Gede Jasa alias Mangku Jasa, terdakwa mendekati korban, I Gede Jasa alias Mangku Jasa, dan pada saat itu terdakwa di salahkan kenapa ngamukngamuk di acaranya yang menambah emosi terdakwa selanjutnya terdakwa dekati dan ayunkan pisau (pengutik) ke arah leher kiri korban, I Gede Jasa alias Mangku Jasa, yang mengenai leher korban, I Gede Jasa alias Mangku Jasa, selanjutnya banyak yang melerai kemudian terdakwa pulang kerumah.

Menimbang bahwa dengan demikian menurut Majelis Hakim unsur dengan rencana Iebih dahulu telah terpenuhi secara sah menurut hukum. Menimbang bahwa oleh karena seluruh unsur Pasal 353 ayat (1) KUHP seperti tersebut dalam Dakwaan Jaksa Penuntut Umum telah terpenuhi dan terbukti secara sah maka Majelis Hakim memperoleh keyakinan bahwa terdakwa telah terbukti secara sah dan meyakinkan bersalah melakukan tindak pidana penganiayaan dengan rencana terlebih dahulu sebagaimana dalam dakwaan Penuntut Umum, maka dakwaan subsider dan seterusnya tidak perlu dipertimbangkan lagi.

Hakim dalam menjatuhkan pidana terhadap terdakwa perlu mempertimbangkannya terlebih dahulu baik keadaan yang memberatkan maupun keadaan yang meringankan terdakwa. Hal-hal yang memberatkan sebagai berikut.

- Perbuatan Terdakwa mengakibatkan saksi korban, I Gede Jasa alias Mangku Gede Jasa, mengalami luka.

Hal-hal meringankan, sebagai berikut.

- Terdakwa sopan dan mengaku terus terang perbuatannya di persidangan.

- Terdakwa belum pernah dihukum.

- Sudah ada perdamaian antara saksi korban korban, I Gede Jasa alias Mangku Gede Jasa, dengan terdakwa yang dituangkan dalam Surat Pernyataan tertanggal 12 Oktober 2018

Hakim memutus perkara Nomor 19/pidB/2019/PNBLI lebih ringan dari tuntutan Jaksa Penuntut Umum adalah karena yang melatar belakangi terjadinya tindak pidana ini memang tidak terlepas dari pengaruh minuman keras (Miras). Disamping itu, terdapat kata-kata yang diucapkan korban kepada terdakwa yang mengakibatkan terdakwa tersinggung sehingga berniat melakukan tindak pidana penganiayaan. Penjatuhan pidana ini bukan bertujuan untuk pembalasan maupun nestapa bagi terdakwa melainkan bersifat preventif edukatif dan korektif serta dapat membawa manfaat bagi masyarakat maupun bagi diri terdakwa sendiri sehingga pada akhirnya terdakwa dapat menyadari kesalahannya dan tidak akan mengulangi lagi kesalahan yang sama di masa yang akan dating.

\section{SIMPULAN DAN SARAN}

\section{Simpulan}

Sanksi pidana terhadap pelaku penganiayaan yang direncanakan adalah pidana penjara maksimal emapt (4) tahun yang telah termuat dalam pasal 353 ayat 1 KUHP sedangkan dalam kasus putusan Nomor 19/pidB/2019/PNBLI yang dibahas pelaku, I Made Merta alias Gadig, dikenakan hukuman pidana penjara selama empat (4) bulan sesuai dalam pasal 353 ayat 1 KUHP dimana unsur-unsur yang terdapat didalamnya semua terpenuhi. Kemudian, dasar pertimbangan hakim dalam pelaku tindak pidana penganiayaan yang direncanakan antara lain Pertimbangan yang bersifat Yuridis yaitu hal-hal yang memberatkan dan hal-hal yang meringankan sedangkan dalam studi kasus putusan Nomor 19/pidB/2019/PNBLI hakim lebih mempertimbangkan riwayat dari terdakwa yaitu terdakwa sopan dan mengaku terus terang perbuatannya di persidangan belum pernah dihukum dan sudah ada perdamaian antara saksi korban, I Gede Jasa alias Mangku Gede Jasa, sehingga hakim menjatuhkan hukuman Pasal 353 KUHP yaitu selama empat (4) bulan.

\section{Saran}

Melalui penelitian ini diharapkan kepada lembaga-lembaga yang terkait untuk bertanggungjawab dalam kasus tindak pidana penganiayaan dalam hal pemberian atau kadar pelanggaran dan hukuman berlaku secara adil. Selain itu, dibutuhkan kondisi penegak hukum yang bebas dari korupsi, suap dan kolusi di seluruh jajaran penegak hukum yang terkait supaya proses pemidanaan bisa memberi efek jera bagi terdakwa sehingga kasus seperti ini tidak ada lagi. Selain itu, diharapkan kepada Majelis Hakim dalam 
memberi putusan tindak pidana penganiayaan diharapkan mempertimbangkan kepentingan bersama agar dengan putusan tersebut dapat menghasilkan kedamaian dan ketentraman bagi masyarakat. Tentunya, bisa memberi efek jera bagi terdakwa dan dapat mengurangi angka tindak pidana penganiayaan di lingkungan masyarakat.

\section{DAFTAR PUSTAKA}

Amirudin, \& Asikin, H. Z. (2012). Pengantar Metode Penelitian Hukum. Jakarta: PT Rajawali Pers.

Benuf, K., \& Azhar, M. (2020). Metodologi Penelitian Hukum sebagai Instrumen Mengurai Permasalahan Hukum Kontemporer. Jurnal Gema Keadilan, 7(1), 20-33.

Fitriani, N. E. (2017). Tinjauan Yuridis Tindak Pidana Penganiayaan terhadap Anak yang Mengakibatkan Luka Berat (Studi Kasus Putusan Nomor 7/Pid.Sus/2015/PN.Tka) (Universitas Hasanuddin Makasar).

Hamzah, A. (2006). Penegakan Hukum Lingkungan. Jakarta: Penerbit Sinar Grafika.

Handoko, B. D. (2020). Pertanggungjawaban Pidana terhadap Pelaku Tindak Pidana Penganiayaan Kepada Anak (Studi Putusan Nomor : 513/Pid.Sus/2017/PN.Plg) (Universitas Muhammadiyah Palembang).

Oktaliza, Y. (2012). Analisis Yuridis Konsep Pertanggungjawaban Pidana terhadap Pembunuhan Berencana yang Dilakukan Anak Dibawah Umur. Jurnal Saburai.

Rifai, A. (2010). Penemuai Hukum. Jakarta: Sinar Grafika.

Sari, G. P. (2019). Tanggung Jawab Pidana Pelaku Tindak Pidana Penganiayaan Mengakibatkan Kematian Yang Melakukan Pembelaan Diri Terhadap Harta Benda (Universitas Sriwijaya).

Wahab, M. T. (2016). Tinjauan Yuridis Terhadap Tindak Pidana Penganiayaan yang Direncanakan Terlebih Dahulu (Studi Kasus Putusan Nomor:1322/Pid.B/2014/PN.Mks) (Universitas Hasanuddin Makasar).

Waluyo, B. (2008). Pidana dan Pemidanaan. Jakarta: Sinar Grafika.

Wijayanto, R. (2012). Asas-Asas Hukum Pidana Indonesia. Bandung: Mandar Maju. 